\title{
The Rising Tide of Women in Urology
}

\author{
Pilar Laguna
}

Department of Urology, Istanbul Medipol University, Turkey

Soc Int Urol J.2021;2(6):339-343

DOI: 10.48083/JHEK4332

I read with pleasure the editorial "A Global Pandemic Is Not Our Only Challenge in Urology" in the January 2021 issue of SIUJ[1]. Indeed, the pandemic has not only challenged us professionally but has also highlighted a social unrest and accelerating global claims at all societal levels. Not least among these are the calls for gender equity and equality in our profession in general, and urology in particular.

I believe the genders possess equal intellectual capacity, the same ability to acquire professional and surgical skills, and the same qualities that lead to a successful career (academic or not). The gender differences in the ways of approaching and solving a conflict-or even the small events of daily life-are, like all diversity, enriching.

Equity, although connected to equality in several respects, is more complex in substance and more difficult to achieve; once achieved, effort must continue if it is to be maintained.

Belonging to the first generation of "women of urology" does not grant me any authority, but it does give me a wider experience and a log-book full of anecdotes. Most laughable, some embarrassing, and a few definitely unpleasant. The last usually the fruit of the limited minds of some male individuals, but a few from females. As a matter of fact, I must disclose that the incident I remember as the most cruelly discriminative came from the mouth of a women-and not so many years ago. Taken together, they illustrate how it has been working in a male-dominated surgical specialty and how some characteristics and attitudes are unfortunately not gender exclusive.

In almost 4 decades working as a urologist, I have witnessed the increasing number of women incorporated into the urology workforce. Very slowly at the beginning, but steadily and more prominently when the Gen X-ers and the first Millennials reached our specialty with a refreshing impetus. Like the excellent young professional females named in the January editorial, we also won prizes, became chairs of departments, were involved in academic work, and did our best to care for our patients. There were a handful of us, likely with different values and perceptions and with fewer opportunities to communicate than today's young professionals. We accepted that it would take some time to become fully integrated in that "male-dominated" world. Nonetheless, paving the way for the next generation of females in urology, that is what we did.

Gender disparity is not a new concern in medicine or in our specialty. A lot has been written exposing the problems and the inequalities, but quite a lot has been done and more is on the way to minimize and remediate the differences.

The urological community started to become seriously concerned about the subject in the late 1990s. Surveys from that time show that although the majority of female urologists encouraged other women to enter the specialty, ultimately $44 \%$ of the potential female graduates or trainee candidates were discouraged at some point. Most believed that gender discrimination had or could have some negative effect on their training and practice, that gender played a limiting role in our specialty, and that there was a lack of adequate mentoring for females[2,3]. Although the information was scant and somewhat subjective, and although neither causality nor remediation was explored or proposed, these reports were the tip of the iceberg and exposed an underlying chronic problem. After these first reports, more information surfaced pointing to different forms of employment and work inequality between female and male urologists, ranging from different salaries for the same workload, practice setting, or fellowship training, and unequal work opportunities, to verbal and other forms of harassment and discrimination. Always detrimental for females-and even more so for those pursuing surgical specialties[4-7].

Differences and possible inequity have also been described in the academic setting. About a decade ago, a PubMed query showed that female residents who graduated as urologists from 2002 to 2009 had fewer publications than their male counterparts and that they were less frequently first authors[8]. The phenomenon is not unique to our specialty and although the rate of overall female authorship in the highest rated journals has 
improved in the last 15 years, it is still half the rate for males in specialties with a more balanced male: female ratio than urology, eg, general oncology[9]. Furthermore, despite the same proportion of women as men pursuing a fellowship and ultimately choosing an academic career, a significantly higher proportion of men than women $(24.7 \%$ versus $2.9 \%)$ attained the rank of associate professor [8].

Most recent data show that in the academic setting, too, professional careers do not turn out as well for females as for males. Of the 2926 US academic urologists who were assistant, associate, or full professors, only $11.2 \%$ were female, and, on average, it took females 1.2 years longer than men to advance from assistant to associate professor [8]. Only gender (not race or ethnicity) was associated with this disparity[10]. The data were in line with previous information on gender-based academic inequity in medicine and in surgery after correcting for possible confounders (number of years since residency completion, graduate degrees, fellowship training, and markers of research production) $[11,12]$.

As the cherry on the sundae, female urologic surgeons have been reported as having fewer children, higher induction rates, and higher incidence of pregnancy complications than women in the general population[13]. In common with female surgeons in other specialties, they are also likely to delay childbearing, and to experience fertility problems and rates of miscarriage up to $38 \%$, which is very high and likely attributable to the demanding nature of the surgical work $[14,15]$. Given this, it is perhaps surprising that although burnout is a major concern in our specialty, it is not more prevalent in female urologists[16,17].

Overall, the literature provides an extensive list of comparative detrimental differences for the female gender in medicine. As female surgeons, we seem to be particularly subjected to offences or frustrations that go beyond inequality to plain and flagrant inequity and discrimination.

Far from ignoring the data, we should strive to analyse how the evidence has been gathered. Yes, there is an association between the variable "female gender" and inequality in urology, but this does not necessarily imply causality. In fact, a non-negligible portion of the information comes from surveys, some with small sample sizes, and it is likely to be influenced by perceptions, which change with time and experience.

If we aim-and we do-to be fully acknowledged, recognized, and integrated into the "urology task force," and to have access to the higher academic ranks and positions of power, the sensitive matter of inequality and inequity deserves a more rigorous and objective approach. Only with honesty, integrity, reflection, and an open and inclusive mind are we going to overcome the challenge.

While all this information points in the direction of "de facto" environmental inequality and lack of equal opportunities for women in urology, much of the extensive body of information does not reflect the current picture. Social and working conditions are not the same now as they were 30 -or even 20 -years ago, and it is undeniable that women have already become visible in urology.

According to the recently released census of the American Urological Association (AUA), females for the first time surpassed $10 \%$ of the urology workforce[18]. Not a lot, but a milestone in a "male-dominated specialty." An unprecedent increase of nearly 50\% in the number of women in urology occurred in the last 5 years, with the higher proportion of female urologists being in the younger age groups[19].

Even more encouraging are the figures just released by the European Association of Urology (EAU) indicating that $16.6 \%$ of their members are women[20]. Although not quantified, the major increase of women in urology over the last few years in Europe has been more than evident. I would even dare to say that the phenomenon started earlier here than in North America. At present, the number of female urology trainees surpasses 50\%, and it is even higher in some European countries-far more than the $24.4 \%$ reported by the AUA[18]. Although this may be the result of women having increased access to medical university places, we cannot ignore the fact that changes in social attitudes about male and female roles and structural modifications in the training and work environment may have had a definitive influence.

There are indeed differences between female and male urologists in patterns of practice, and gender shapes the clinical landscape. Women more frequently subspecialize in female urology and work in academic centers and in metropolitan areas[21,22]. According to the AUA census, women already account for $46.5 \%$ in female pelvic medicine and reconstructive surgery (FPMRS) $[18,23]$. Considering the female prevalence in the AUA Task Force report, this is disproportionate[18]. Whether the choice is driven by personal preferences or patient preferences or is imposed by restrictive access to other subspecialties is unknown, but inevitably, it is going to skew the prevalence of females in other subspecialties. Of note, FPMRS also had the highest proportion of members of groups categorized as "underrepresented in medicine" (URiM) compared with the other subspecialties[23].

In Canada, a country with high social equality standards, there are significantly more male than female academic urologists. A retrospective study published in 
2020 found that as academic rank increases, the proportion of female urologists decreases, and male urologists have significantly higher academic ranks, h-index values, number of publications, and citations. The lack of females in senior academic leadership is not surprising given that the history of females in urology goes back only 50 years $[24,25]$. The accompanying editorial stresses the need to clarify the reported gender discrepancies in academic urology and incorporate different measures of academic productivity such as educational and continuing medical education (CME) activities. Moreover, the authors make a plea for considering ability, talent, dedication, and innovation above gender[25].

Female urologists are increasingly included in working groups and panels in international meetings[20] with 2021 seeming to be a turning point. The American College of Surgeons is planning measures to address inequities that affect women in medicine and those who are seeking to enter the profession[26]. Major journals and important health institutions have echoed the need for inclusion and diversity and taken measures to promote equity and equality at all levels of medicine $[27,28]$.

In 2020, at least 4 prestigious awards were given to brilliant female urologists-role models practicing in subspecialties beyond the ones conventionally reserved for female urologists. So far in 2021, 4 "women of urology" have been recognized by the AUA: Catherine R. deVries with the Humanitarian Recognition Award of the AUA Urology Care Foundation; Tracey L. Krupski with the Robert C. Flanigan Education Award; MaryAnn Lynn Stothers with the Victor A. Politano Award; and Stacy Loeb with the Gold Cystoscope Award. In Europe, Véronique Phé, a young female urologist, received the prestigious EAU Crystal Matula Award.

Also, the Society of Women in Urology turns 40 this year. SIU has had women on its Board for many years, and for the last 4 years, the Society's Scientific Committee has devoted special attention to inclusivity and diversity. This without forgetting all the "women of urology" who have become chairs, professors, and academicians. Thus, it seems clear to me that we do not need to be indoctrinated in how to become "women in the lead," because we are not doing so badly.
On February 9, 2019, the Lancet dedicated an issue to women in medicine that included an enjoyable piece entitled "Working toward gender diversity and inclusion in medicine: myths and solutions"[29]. It is about the major myths that prevent diversity and inclusion and the possible solutions beyond individual behavior. It is also about the need to see the problem beyond the number of women in the field and to create lasting changes based on fair and transparent institutional policies, on the commitment of all involved parties to change group dynamics, on changes in societal values, and on understanding that promoting diversity does not contravene meritocracy.

I would like to finish by mentioning briefly a disturbing phenomenon that is no doubt familiar to you, namely, the "manel," or panel consisting only of men. They are unbalanced and exclusive, but the same applies to the "wanels," which do now exist. Both are toxic and equally discriminative. The latter may be even worse because of the implicit and troubling tokenism. I hear with concern the increasingly raised voices of both males and females, expressing dissatisfaction and discomfort. The former afraid they will be discriminated against in the interests of redressing the balance, and the latter afraid they will be invited only because they are women. And I do not like it. Although some think that numbers are irrelevant when equity is the issue, the truth is that we have used them to build up our case, so we should be consistent in using them to measure our progress.

In summary, the turmoil regarding disparity and the need for diversity and equity-for all underrepresented groups-has never been so evident and urgent as it is now. The speed of media diffusion and the increasing penetration of these groups makes it different from the past. It seems to me that we females are navigating quite well in the ocean of our specialty, but there is still a lot to do. All of us - male and female-must do the work well, ensure that we have a solid vessel, remain steadfast at the helm, and modify the course to avoid the storms.

Finally, I have nothing but praise and thanks to offer the major societies in urology-EAU, AUA, SIU, the Endourological Society, and the many others-that have never made me feel discriminated against. 


\section{References}

1. Black P. A global pandemic is not our only challenge in Urology. Soc Int Urol J.2021;2:5-6. DOl: https://doi.org/10.48083/G0ZD2340

2. Bradbury CL, King DK, Middleton RG. Female urologists: a growing population. J Urol.1997;157: 1854-1856.

3. Lightner DJ, Terris MK, Tsao AK, Naughton CK, Lohse CM. Status of women in urology: based on a report to the Society of University Urologists. J Urol.2005 Feb;173(2):560-563. doi: 10.1097/01. ju.0000149739.51103.d3.

4. Spencer ES, Deal AM, Pruthi NR, Gonzalez CM, Kirby EW, Langston J, et al. Gender differences in compensation, job satisfaction and other practice patterns in urology. J Urol.2016 Feb;195(2):450-455. doi: 10.1016/j.juro.2015.08.100. Epub 2015 Sep 15.

5. Schlik CJR, Ellis RJ, Etkin CD, Greenberg CC, Greenberg JA, Turner $\mathrm{PL}$, et al. Experiences of gender discrimination and sexual harassment among residents in general surgery programs across US. JAMA Surg.2021Jul;28:e213195. doi: 10.1001/jamasurg.2021.3195. Online ahead of print.

6. Myers SP, Dasari M, Brown JB. Effects of gender bias and stereotypes in surgical training: a randomized clinical trial. JAMA Surg.2020;155(7):552-560.

7. Dossa F, Simpson AN, Sutradhar R, Urbach DR, Tomlinson G, Detsky AS, et al. Sex-based disparities in the hourly earnings of surgeons in the fee-for-service system in Ontario, Canada. JAMA Surg.2019 Dec 1;154(12):1134-1142. doi: 10.1001/jamasurg.2019.3769.

8. Yang G, Villalta JD, Weiss DA, Caroll PR, Breyer BN. Gender differences in academic productivity and academic career choice among urology residents. J Urol.2012;188:1286-1290.

9. Yalamanchali A, Zhang ES, Jagsi R. Trends in female authorship in major journals of 3 oncology disciplines. JAMA Network Open.2021;4(4):e212252.

10. Breyer BN, Butler C, Fang R, Meeks W, Porten SP, North AC, et al. Promotion disparities in academic urology. Urology.2020 Apr;138:1623. doi: 10.1016/j.urology.2019.10.042. Epub 2020 Jan 7.

11. Gawad N, Tran A, Martel AB, Baxter NN, Allen M, Manhas N, et al. Gender and academic promotion of Canadian general surgeons: a cross-sectional study. CMAJ Open.2020 Jan 28:8(1):E34-E40. doi: 10.9778/cmajo.20190090. Print Jan-Mar 2020.
12. Jena $A B$, Khullar D, Ho O, Olenski AR, Blumenthal DM. Sex differences in academic rank in US medical schools in 2014. JAMA. 2015Sep;15;314(11):1149-1158. doi: 10.1001/jama.2015.10680.

13. Lerner LB, Baltrushes RJ, Stolzmann KL, Garshick E. Satisfaction of women urologists with maternity leave and childbirth timing. J Urol.2010 Jan;183(1):282-286. doi: 10.1016/j.juro.2009.08.113.

14. Phillips EA, Nimeh T, Braga J, Lerner LB. Does a surgical career affect a woman's childbearing and fertility? A report on pregnancy and fertility trends among female surgeons. J Am Coll Surg.2014;219:944-950.

15. Poon S, Luong M, Hargett D, Lorimer S, Nguyen C, Payares M, Friedman S. Does a career in orthopaedic surgery affect a woman's fertility? Orthop Surg.2021;29(5):e243-e250. doi: 10.5435/JAAOS-D-20-00198.

16. Ilin J, Langlois E, Jalal S, Khosa F. Gender disparity within academic Canadian urology. Can Urol Assoc J.2020;14:106-110.

17. Cox A, Siemens DR. Continued gender disparity in urology? Only time will tell. Can Urol Assoc J.2020;14(4):79-80. doi: 10.5489/cuaj.6519. Epub 2020 Apr 1.

18. American Urological Association (AUA) 2020 Annual Census Report, "The state of the urology workforce and practice in the United States. American Urological Association, 2020. Available at: https://www. auanet.org/research/research-resources/aua-census/census-results. Accessed September 25, 2021.

19. Female urologists make history in urology. News release. American Urological Association. May 27, 2021. Available at: http://auanet. mediaroom.com/2021-05-27-Female-Urologists-Make-History-inUrology\#.YK-qH1V3eEw.twitter. Accessed September 25, 2021.

20. Chapple CR, Albers P, Denstedt J. Addressing equality of representation in urology societies. Eur Urol.2021 Oct;80(4):454-455. https://doi. org/10.1016/j.eururo.2021.07.001

21. Saltzman A, Hebert K, Richman A, Prats S, Togami J, Rickey L, et al. Women urologists: changing trends in the workforce. Urology.2016 May;91:1-5. doi: 10.1016/j.urology.2016.01.035. Epub 2016 Mar 4.

22. Oberlin DT, Vo AX, Bachrach L, Flury SC. The gender divide:.the impact of surgeon gender on surgical practice patterns in urology. $J$ Urol.2016 Nov;196(5):1522-1526.doi: 10.1016/j.juro.2016.05.030. Epub 2016 May 10. 
23. Dielubanza EJ, Enemchukwu EA, Atiemo HO. Urology workforce diversity in female pelvic medicine and reconstructive surgery: an analysis of the American Urological Association census data. Urology.2021 Jul 15;S0090-4295(21)00641-5. doi: 10.1016/j. urology.2021.06.031. Epub ahead of print.

24. Franc-Guimond J, McNeil B, Schlossberg SM, North AC, Sener A. Urologist burnout: frequency, causes and potential solutions to an unspoken entity. Can Urol Assoc J.2018;12:137-142. Published online 2017 Dec 22. doi: 10.5489/cuaj.4668

25. Marchalik D, Goldman CC, Carvalho FFL, Talso M, Lynch JH, Francesco Esperto F, et al. Resident burnout in USA and Europe urology residents: an international concern. BJU Int.2019 Aug;124(2):349-356. doi: 10.1111/bju.14774. Epub 2019 May 8.

26. Stephens EH, Heisler CA, Temkin SM, Miller P. The current status of women in surgery: how to affect the future. JAMA Surg. 2020;155:876-885.
27. Fontanarosa PB, Flanagin A, Ayanian JZ, Bonow RO, Bressler NM, Christakis D, et al. Equity and the JAMA Network. JAMA Surg.2021 Aug 1;156(8):705-707. doi: 10.1001/jamasurg.2021.3098.

28. The Editors of the Lancet Group. The Lancet Group's commitments to gender equity and diversity. Lancet.2019 Aug 10;394(10197):452-453. doi: 10.1016/S0140-6736(19)31797-0. Epub 2019 Aug 8.

29. Kang SK, Kaplan S. Working toward gender diversity and inclusion in medicine: myths and solutions. Lancet.2019 Feb 9;393(10171):579_ 586.doi: 10.1016/S0140-6736(18)33138-6 